\title{
ANUARIO LOpe
}

\section{LOS BANDOS DE SENA: UN MOSAICO POR RECONSTRUIR}

\author{
LuCiANA Gentilli (Università di Macerata)
}

Cita Recomendada: Luciana Gentilli, «Los bandos de Sena: un mosaico por reconstruir», Anuario Lope de Vega. Texto, literatura, cultura, XXV (2019), pp. 34-54.

DOI: $\leq$ https://doi.org/10.5565/rev/anuariolopedevega.313>

Fecha de recepción: 18 de julio de 2018 / Fecha de aceptación: 29 de septiembre de 2018

\section{RESUMEN}

El presente trabajo tiene como objetivo reconstruir el complejo proceso genético de Los bandos de Sena de Lope de Vega, pieza compuesta entre 1597 y 1603, a partir de la novella 49 de la Parte I de la colección bandelliana, tratando a la vez de poner al descubierto la diversificación argumental y la singular recomposición de la antigua leyenda senesa por él realizada.

Palabras Clave: Lope de Vega; Los Bandos de Sena; Gentile Sermini; Bernardo Lapini; Scipione Bargagli; Matteo Bandello; François de Belleforest; La novella di Angelica Montanini.

\section{ABSTRACT}

This paper will depict the complex genetic process behind Lope de Vega's Los bandos de Sena (written between 1597 and 1603, and based on Novella 49 belonging to Part I of Bandello's collection of short stories), with the aim of shedding light on the author's departure from the old senese legend and his unique interpretation of the tale.

KeYwords: Lope de Vega; Los Bandos de Sena; Gentile Sermini; Bernardo Lapini; Scipione Bargagli; Matteo Bandello; François de Belleforest; La novella di Angelica Montanini. 
$\mathrm{L}$ as desalentadas palabras con las que Emilio Cotarelo reconoce su incapacidad para reconstruir los avatares por los que debieron pasar Los bandos de Sena, pieza publicada en la Veintiuna parte verdadera, aparecida en Madrid (viuda de Alonso Martín) a las pocas semanas de morir el Fénix, en 1635, emblematizan de forma elocuente las dificultades existentes para establecer filiaciones:

La comedia es de asunto italiano y de fondo histórico, tomado de los frecuentes disturbios y banderías políticas en las ciudades libres de aquel país [...] Quizá Lope haya tomado el asunto de algún novelista italiano, aunque no lo hemos hallado, sin duda por torpeza nuestra, ni en el Bandello, ni en Sacchetti, el Lasca, el Boccaccio, el Pecorone y otros que hemos revisado. (Cotarelo y Mori 1917:xxiii-xxiv)

A decir verdad, tampoco la abundante cosecha de estudios e investigaciones, dedicados en estos últimos años al diálogo intertextual mantenido por Lope con los novellieri italianos, ofrece muchos datos al respecto. Lo que se sabe con certeza es que Los bandos de Sena, compuesta según Morley y Bruerton entre 1597 y 1603, forma parte del numeroso elenco de piezas lopianas fundadas en la fecunda explotación de la rica vena de los cuentistas italianos. Tanto Carmen Hernández Valcárcel [s.a.] como Guillermo Carrascón [2016:48] y Juan Ramón Muñoz Sánchez [2013], retomando algunas indicaciones ya formuladas en su tiempo entre otros por Menéndez y Pelayo [1907:xxi] y Arróniz [1969:299], consideran que el argumento de esta comedia se remonta a la novella 49 de la Parte I de las obras de Matteo Bandello. Los bandos, pues, sería una prueba más de la profunda huella dejada por el fraile dominico de Castelnuovo Scrivia en el teatro lopiano, puesto que al menos diecisiete comedias suyas, según las recientes pesquisas efectuadas por Muñoz Sánchez [2013:132], tienen su origen en la inagotable cantera del obispo de Agen.

A la luz de lo dicho, me gustaría aportar en esta circunstancia mi personal grano de arena a fin de aclarar algunos aspectos del proceso genético de esta pieza, tratando de seguir el rastro de su amplia y tortuosa red de conexiones textuales y, a la vez, de poner al descubierto la diversificación argumental y la singular recomposición realizada por el Fénix. 
El argumento de la novella 49 de la Parte I de la colección bandelliana, titulada Anselmo Salimbene magnificamente operando libera il suo nemico da la morte e la sorella di quello prende per moglie, cuenta con una vasta tradición de testimonios literarios, arraigada en la historia autóctona de Siena (cfr. Marchi 2017:11-24). Esta antigua leyenda ciudadana, conocida también como La novella di Angelica Montanini, un cuento disgregado a medio camino entre la historia vera y la fabula ficta, nos ofrece la detallada reconstrucción de una noble competición alrededor de la virtud de la liberalidad, con su estela de obligaciones y deudas de gratitud que ponen a dura prueba al amator liberalitatis. Los tres protagonistas son Anselmo Salimbene, perteneciente a la antigua familia de magnates sieneses, Carlo Montanini y su hermana Angelica, descendientes de uno de los más insignes linajes ciudadanos - los Montanini-, que formaban parte del Consejo de los Nueve. En aras de la claridad, cabe decir en seguida que Bandello es el único autor extraciudadano, ya que las otras cuatro versiones de las que hasta el momento tenemos noticia se deben todas a la pluma de escritores sieneses.

La primera redacción de la novella forma parte de una colección de cuarenta cuentos, compuestos en la primera mitad del siglo $\mathrm{xv}^{1} \mathrm{y}$ atribuidos a Gentile Sermini, phantom author o quizá nom de plume, ${ }^{2}$ al que debemos la formulación más lineal y concisa de la historia. Como bien se desprende del título propuesto para la novella catorce -Anselmo, amando Angelica, fece a Carlo suo fratello una gran cortesia; et simile Carlo et Angelica a llui et lui a lloro, ciascuno a prova, per non essere ingrato, tante cortesie si fecero che pendente rimane qual di quelle fusse maggiore. La qual determinazione al leggitore se n'adomanda - (pseudo Sermini, Novella $X I V$, p. 73), la materia diegética se configura como un tema controversial, puesto que se indaga ex comparatione sobre quién es más liberal. El enredo argumental es muy sencillo y, dado que la estructura del cuento no experimenta variaciones importantes a lo largo de su afortunada trayectoria redaccional, resulta quizá oportuno ofrecer una escueta síntesis de su traza primigenia. En la narración del pseudo Sermini, Anselmo aparece descrito como un joven de la ilustre casa de los Salimbe-

1 La primera impresión - Novelle di Gentile Sermini da Siena ora per la prima volta raccolte e pubblicate nella loro integrità - vio la luz solo en 1874 en Livorno. Para más información sobre este escritor cfr. Marchi [2011].

2 Sobre la posible atribución del novelliere al literato, político y diplomático sienés Andreoccio Petrucci, muerto en Siena durante una epidemia de peste en 1449, cfr. Pertici [2013]. 
ne, «bello del corpo»y «richissimo» (p. 73), profundamente enamorado de Angelica Montanini, noble y honrada doncella que, al haber quedado huérfana, solo podía contar con el sostén de su hermano Carlo y con los escasos beneficios procedentes de una finca — «possessione»- que ambos tenían en el campo, en los entornos de Siena. Un día, durante una riña, Carlo hiere a otro conciudadano suyo, razón por la cual se ve detenido y obligado a pagar una multa de mil fiorini (p. 73), so pena de la amputación de la mano derecha. Determinado a reconquistar la libertad, el joven decide vender su posesión, del valor de unos mil fiorini, a un vecino suyo, que desde hacía mucho tiempo anhelaba apoderarse de ella; sin embargo el codicioso individuo aprovecha la ocasión para hacerse con la propiedad por solo «800 fiorini» (p. 74). En su ayuda acude Anselmo, que paga la sanción sin pedir nada a cambio. Deseoso de recompensar semejante acto de magnanimidad, Carlo está dispuesto a deshacerse de todos sus bienes, pero el noble rechaza cualquier oferta. Al enterarse, por fin, de que Anselmo está prendado de Angelica, Carlo decide entregarle a su virginal hermana. En este cuento, empero, la conducta caballeresca no sufre merma: es así que cuando Anselmo, ya en la cama, está a punto de tomar posesión de la inocente muchacha, súbitamente se arrepiente y, dando muestra de gran entereza, le propone convertirse en su «sposo et marito» (p. 78). La narración termina con las bodas de la pareja y con la recuperación por parte de Carlo de su estatus de rico prohombre, puesto que Anselmo acabará repartiendo su caudal con su amigo y cuñado. El cierre de la historia de Angelica Montanini no se corresponde, sin embargo, con la conclusión de la novela, ya que la solutio de la disputa, queda virtualmente encomendada, a manera de colofón, a los futuros lectores: «Hora, considerate tutte le nominate cortesie usate fra loro, resta da ssolvare et terminare qual fusse la maggiore et la più conmendabile» (p. 81).

La idea de transformar la materia objeto de la disputatio en el propio núcleo narrativo de la novella —una especie de disputatio en acción- encuentra su cabal realización con Bernardo Lapini, llamado el Ilicino (1418/33-1476), ${ }^{3}$ en cuanto originario de Montalcino, el burgo toscano que más de medio siglo después se convertirá en el fulcro de la resistencia antimedicea durante la guerra de Siena (15521559). Este médico literato gozará de buena fama en España, en cuanto autor del

3 Para más información sobre el autor véase la bibliografía indicada por Cracolici [2009:109, nota 1]. 
más célebre comentario del Cuatrocientos a los Triumphi del Petrarca, texto compuesto en la corte ferraresa de Borso d'Este entre 1468 y $1469 .{ }^{4}$ De la pluma de Lapini proceden también dos novelas: La vita di Madonna Onorata y la mejor - sobre todo la que más nos interesa en esta circunstancia-, la Opera dilettevole e nuova della cortesia, gratitudine et liberalità, publicada en Siena en 1511, y más tarde en Venecia en 1513, 1515 y 1611 (Marchi 2017:142-146).

Ahora bien, el intento del Ilicino no fue tanto el de entretener a sus lectores, recreando sus espíritus a través de una amena novelletta, sino el de ofrecer una ejercitación de habilidad oratoria, organizada según el método disputativo de la quaestio, ya en boga en la clasicidad y a lo largo de toda la Edad Media. «Disputatio —se afirmaba en el De fallaciis (cap. I), atribuido a Santo Tomás- est actus syllogisticus unius ad alterum ad aliquod propositum ostendendum». La Opera dilettevole se abre con una carta proemial, dirigida a una no especificada «illustrissima prencipessa» (Bernardo Lapini, La Novella di Angelica Montanini, p. 85), conmemorativa de los preclaros orígenes de Siena, ciudad fundada según la leyenda por los sobrinos de Rómulo, en que se ofrece información sobre «un caso intervenuto [...] infra di due gentili homini sanesi, et dipoi revocato in dubio et factosi di quello da tre singularissime giovane notabile disputatione» (pp. 89-90). En opinión del redactor del proemio, la disputa habría tenido lugar en una velada cortesana, al clausurarse un banquete nupcial, configurándose, pues, como un típico pasatiempo de salón - recuérdense las célebres veladas sienesas-y como ejemplo de civil conversación. Magistra de la discusión y a la vez narradora del relato es una reverenda matrona, orquestadora de la novella en forma de «declamatio de liberalitate» (Badioli 2000). Gracias a su voz los oyentes del casus van descubriendo los antecedentes del suceso, es decir la batida de caza organizada por unos jóvenes de las muy nobles familias Salimbeni y Montanini, durante la cual se produjo un altercado sobre a cuál de las dos manadas de perros debía atribuirse la palma por haber matado a un feroz jabalí. La proeza cinegética fue, pues, el desencadenante de la sangrienta contienda que durante años contrapuso a los dos clanes sieneses, determinando al final la ruina de la casa de los Montanini. A la voz narrativa se deben también otros significativos detalles de la historia, ausentes en la versión del pseu-

4 Sobre la recepción del comentario del Ilicino en España véanse Francalanci [2006 y 2008] y Valero Moreno [2009]. 
do Sermini: la fijación de un exacto marco espacio-temporal —Siena en el año 1395-; la connotación política del ciudadano oportunista y desleal, en cuanto miembro de la facción de los populares y, sobre todo el mayor protagonismo de Angelica. El personaje inventado por Bernardo Lapini ya no es la mujer frágil y pasiva de su conterráneo, el pseudo Sermini, sino una figura femenina de fuerte personalidad, determinada a darse muerte cruel en cuanto su hermano la ofrezca al antiguo rival Anselmo, como prenda de su inmensa gratitud por haberle salvado la vida. Amplio espacio, además, queda reservado a los alardes argumentativos de las tres damas, que en la parte conclusiva del relato protagonizan el debate deliberativo sobre «chi merita maggiore laude di cortesia, o Carlo, o Angelica, o veramente Anselmo» (p. 111), sin llegar no obstante a la resolución de la contentio.

En opinión de Monica Marchi [2017:47], la novella del Ilicino sería también la fuente textual de la versión propuesta por el anónimo redactor de los Annali sanesi, registrada en el año 1395. Según dicha estudiosa se trataría de una verdadera refundición, lindante con el plagio, de la que no se habría dado cuenta ni siquiera Ludovico Antonio Muratori en su edición, en 1731, del volumen XIX de los Rerum Italicarum Scriptores. La superposición entre las dos versiones se patentiza ya a partir del mismo antefatto de la historia, que reproduzco a continuación en cuanto prueba palpable de lo dicho:

Salinbeni et Montanini, [...] ritrovandosi insieme a una nobilissima caccia più numero di giovani dell'una e della altra fameglia, essendo stato morto dai cani uno cinghiale ferocissimo, et venendo a contendare della prodeza de' cani, occorse doppo molte parole che uno de' Montanini ferì a morte uno giovano de' Salimbeni, per la cui occisione nascendone mortale inimicitia, intervenne che in poco tempo la casa de' Montanini fu data quasi ad extrema ruina. (Bernardo Lapini, La novella di Angelica Montanini, p. 94)

Salimbeni e Montanini, trovandosi insieme a una nobile e bella caccia più numero di gioveni dell'una parte e dell'altra, e essendo stato morto un gran cignale accanato, contendendo della prodezza de' cani, occorse che un de' Montanini per questa differenza ferì a morte uno de' Salimbeni, per la di cui offesa crescendone mortale inimicizia, intervenne che in poco tempo la casa de' Montanini fu data a estrema ruina. (Anonimo Senese, La storia di Angelica Montanini, p. 183) 
Lo que aparece incontestable, perfilándose además como cifra representativa de este relato, es la estrecha interconexión que se produce entre res factae y res fictae o, mejor dicho, la presentación de algo ficcional como realmente acontecido. En efecto, esta mezcolanza no se da solo en los Annali sanesi, sino también en Le Pompe sanesi, o'vero Relazione delli huomini e donne illustri di Siena, obra del dominico Isidoro Ugurgieri Azzolini (Pier'Antonio Fortunati, Pistoia, 1649). En el capítulo XXXII de la II parte de sus crónicas, dedicado a los «Sanesi chiari per magnificenza e generosità», el teólogo y consultor del Santo Oficio nos cuenta, ya en pleno siglo xviI, la «generosa azzione» protagonizada por Anselmo Salimbeni de' Grandi di Siena, «la quale per se medesima è sufficente a collocarlo tra' Sanesi chiari per Magnificenza, e liberalità» (§VI, p. 319).

En una perspectiva de continuidad y diferencia la exitosa irradiación de la Opera dilettevole de Bernardo Ilicino nos brinda dos ejemplos más de imitatio creativa en la cuentística italiana del Renacimiento: la novella 49 (Parte I) de Matteo Bandello, sobre la que me detendré dentro de poco, y el cuento compuesto por Scipione Bargagli (1540-1612). El escritor sienés — perteneciente a la llamada «generación del asedio» (Riccò 1989:xxvii) en memoria de la rebelión antiespañola y de la larga resistencia a la anexión medicea impuesta por Cosimo I (19 de julio de 1557), «Duce» de la efímera Accademia degli Accesi (1558-1568) y más tarde, en 1603, miembro de la resucitada Accademia degli Intronati, debe buena parte de su fama literaria a la publicación en 1578 de su tratado Delle imprese (Luca Bonetti, Siena) y en 1587 (Bernardo Giunti, Venecia) de I trattenimenti (dove da vaghe donne e da giovani uomini rappresentati sono onesti e dilettevoli giuochi, narrate novelle e cantate alcune amorose canzonette), obra en la que una «eletta brigata» juvenil (Riccò 1989:xv) se las ingenia para amenizar los últimos tres días del Carnaval sienés de 1555, durante el terrible sitio de la ciudad, con juegos, debates sobre cuestiones de amor, rimas ocasionales, agudas empresas y el cuento de seis novellette, en la mayoría de raigambre bandelliana (Riccò 2013:90). Interesante corolario de este corpus es la larga novella suelta dedicada a las peripecias de Angelica y Carlo Montanini, cuya resonancia sin embargo debió de ser bastante limitada, puesto que, de haber circulado, fue solo de forma manuscrita. ${ }^{5} \mathrm{El}$ cuento de Bargagli, como atinadamente sugiere Riccò [1989:558-559], es una acertada combinación entre el texto del Ilicino

5 Novella di Carlo Montanini e Anselmo Salimbeni. Cod. P. IV. 27. n. 1 della Com. di Siena. 
y el de Bandello: «la lettera introduttiva è di tipo bandelliano, la premessa narrativa iliciniana, il nucleo centrale, la novella in senso stretto, passa attraverso il capillare assorbimento del Bandello [...]; infine il dibattito conclusivo è di nuovo desunto dall'Ilicino». Sin embargo, pese a esa equilibrada conformidad con modelos y artificios ya experimentados, lo que resulta más llamativo es la indudable primacía de la instancia juzgadora. En Bargagli la raccontazione es funcional a la disputa y a la formulación de los iudicia liberalitatis, aspecto este propio del modus operandi escolástico, tan apreciado en los torneos de pensamientos de las célebres academias sienesas, como puede observarse en el anuncio del caso sobre el cual se basa la misma narración: «un singularissimo caso di più magnanimità e cortesie usate infra due gentiluomini e d'alto sangue sanesi, con una notabile disputazione fatta da tre egregie giovani donne sopra ' l detto caso, avvenuto negli anni domini MCCCLXXXXV a dì primo di gennaio» (Scipione Bargagli, La novella di Angelica Montanini, p. 38).

Fijémonos ahora en el remake efectuado por Matteo Bandello. La carta dedicatoria, que introduce la novela 49 (Parte I, Busdrago, Lucca, 1554), dirigida al sienés Agostino Chigi, el célebre banquero de los Papas, aquilata la presunta veracidad del relato, puesto que el escritor afirma haber escuchado el suceso en Sabbioneta de la voz del gentilhombre mantuano Antonio di Cappo, a petición de Antonia Bauzia, marquesa de Gonzaga. Además Bandello no esconde la trabazón motivadora de su diseño narrativo, es decir, rendir homenaje a Chigi, inigualable campeón de liberalidad. ${ }^{6}$ En cuanto al uso de la materia diegética, es incuestionable la capacidad del autor para expandir la fuente iliciniana por lo que atañe a las intervenciones de los personajes y a la pluralidad de subtemas y episodios insertados. Cada figura o situación por él acuñada refulge gracias a sus cuidadosas pinceladas, denotativas del carácter o de la coyuntura evocados. Esto es lo que sucede, por ejemplo, con la reconstrucción de la «solenne caccia di cervi e di cinghiari» y de la cadena de asesinatos por aquella originada, causa primigenia de la «crudelissina nemicizia» (p. 199) que durante años enfrentó a las familias de los Salimbeni y de los Montanini. Sin lugar a dudas son principalmente los tres protagonistas los que se ven enriquecidos con nuevos matices, identificativos de su ser y condición: el semblante de Carlo es espejo revelador de la «leggiadria dei costumi» y de la antigua grandeza de sus an-

6 «Mi pare che a voi meritamente si convenga, che sète e liberale e cortese, anzi la gloria d'ogni cortesia e liberalità, e non solo sète l'onore de la patria vostra Siena, ma sète l'onor e la gloria di tutta Italia» (Matteo Bandello, Novella XLIX, p. 198). 
cestros; en virtud de la ecuación nomen omen, Angelica se nos presenta como «la più bella e meglio costumata giovanetta che si trovasse a quei tempi in Siena» (p. 200); ni que decir tiene que en esta competición para acceder a los más altos grados de perfección, Anselmo también sobresale por «nobiltà e ricchezze di molta stima» (p. 200), pero sobre todo por la firmeza de su amor hacia Angelica. Lo que más me interesa destacar es empero la perfilada identidad asumida en esta versión por el «cittadino popolare», el infame arquitecto de la mortal trampa tendida contra el joven Montanini, que había recibido solo una somera atención por parte de los otros novellieri. El personaje, definido por Bandello «maligno», «ribaldo», «ingordo» (p. 201), se nos antoja como un digno precursor del Faustino de Lope. La secuencia en cambio, en la que el fraile dominico se extrema en la más llamativa dilatatio materiae, es la del acalorado coloquio entre los dos hermanos Montanini: «messe in contingenza l'honestà della sorella e l'honore della famiglia», Carlo no duda en autoproclamarse esclavo de su auxiliador, imponiendo a Angelica entregarse al «potere e total arbitrio d'Anselmo Salimbene» (p. 211). En esta ocasión Bandello pone al descubierto «il lato oscuro» (Menetti 2005:185) que se esconde detrás de este gesto liberal y magnánimo, es decir la condenación impuesta a Angelica por su mismo hermano a convertirse en «bagascia vituperosa e donna di volgo» (p. 213), en caso de que acceda a conceder a Anselmo el irrecuperable tesoro de su doncellez.

Según Marchi [2017:44] lo que más diferencia y aleja el cuento bandelliano del molde ofrecido por el Ilicino es sobre todo el hecho de que su novella no resulta organizada sub specie quaestionis: en su opinión, pues, el dominico no parece interesado en cotejar las proposiciones a favor o en contra, ni en emprender un tour de force oratorio, convirtiendo la cornice en mero trampolín donde encajar su propia historia y «lasciando ai filosofi, come era appunto l'Ilicino, l'onere di giudicare se quelle azioni lodevoli siano da ritenersi "magnifiche" piuttosto che "liberali" o "cortesi"» (p. 199). Ahora bien, si corresponde a la verdad el hecho de que Bandello suprime el articulado debate final mantenido entre las tres damas, conformándose con un tajante cierre - «ora si potrebbe disputare qual sia più di lor tre da esser lodato e qual di loro usò maggior cortesia ne le cose che da me udite avete» (p. 219)— más en línea con la originaria versión del pseudo Sermini, no creo posible, no obstante, descartar totalmente la influencia ejercitada en su obra por l'esprit de controverse. La explícita apelación al magisterio de Boccaccio, puesta en apertura del relato — «seguitando le pedate del nostro gentilissimo Boccaccio, parliamo 
d'amore e veggiamo quanto magnificamente con liberalità lodevole un gentiluomo operasse» (p. 199)—, da a entender una voluntad de englobar en el mismo desarrollo del argumento, a través del variado proceder de los distintos personajes, la exposición de los posibles enfoques desde los que abordar el tratamiento del caso seleccionado. Como afirmaba Edoardo Sanguineti [2000:56], al hablar de la obra cumbre del certaldese, «le cento novelle sono proprio cento quaestiones e conviene leggerle come una catena di cento problemi [...] raccolti e registrati in adeguati "schemata", per essere prodotti e sottoposti a un giudizio e a una valutazione collettivi [...] tutt'altro che obbligatoriamente unanimi». Desde esta perspectiva la novella $49 \mathrm{de}$ la Parte I podría considerarse como una pieza tributaria del amplio repertorio de casuística amorosa o, como sugiere el mismo Sanguineti [2000:56], refiriéndose al Decameron, una «quaestio imborghesita».

A fin de recomponer la urdimbre intertextual de la novella de Angelica Montanini convendrá repasar también las versiones contrarreformistas del cuento, en cuanto probatorias tanto de su difusión como de su capacidad de actuación en contextos culturales diferentes. Me refiero a la novela 35 del Primo volume delle novelle del Bandello nuovamente ristampato, e con diligenza corretto. Con una aggiunta d'alcuni sensi morali dal S. Ascanio Centorio degli Ortensi (Giovan Antonio degli Antonii, Milán, 1560); a su homóloga, es decir la novela 35 de la nueva edición del Primo volume delle novelle del Bandello al cuidado de Alfonso Ulloa (Camillo Franceschini, Venecia, 1566), y finalmente a la paráfrasis francesa realizada por François de Belleforest (Robert Le Mangnier, París, 1566). Ahora bien, si la novela, tanto en la edición confeccionada por Centorio como en la de Ulloa, mantiene el mismo título elegido por Bandello (Anselmo Salimbene, magnificamente operando, libera il suo nemico dalla morte, e la sorella di quello prende per moglie) y no se despega de la fuente en cuanto al hilo argumental, cabe señalar sin embargo cómo las mayores diversificaciones se producen en el ámbito paratextual (cfr. Loi 2015): omisión de la carta dedicatoria y del prólogo, o parte proemial — trait d'union del díptico carta-novela-, y, sobre todo, adición del senso morale, verdadera cifra del proceso de resemantización al que es sometido el cuento. Gracias a la re-lectura moralizadora efectuada por Centorio y retomada por Ulloa, los tres protagonistas de la historia mediatizan la imagen arquetípica del noble generoso que, en palabras de Stefano Guazzo (La civil conversazione, 1574, lib. II, p. 132), «non degenera dalla natura di se stesso", transformando la novelletta en un sintético breviario de normas compor- 
tamentales y haciendo a la vez tabula rasa del antiguo modelo de la quaestio disputata tan importante en su fase auroral.

La Histoire XXI, aparecida en 1566 en Le second tome des Histoires Tragiques (Robert Le Mangnier, París), ${ }^{7}$ discurre en cambio por inéditos derroteros. Ya a partir del título -Acte genereux d'un Gentilhomme Sienois, lequel deliura son ennemy de la mort, et l'autre qui luy feist present de sa sœur, de laquelle il le sçauoit estre amoureux_, el code-switching — por así llamarlo—operado por Belleforest se patentiza de manera impactante. En su intención la historia de Carlo y Angelica Montanini o, para ser más correctos, de Charles y Angelique, puesto que el adaptador traduce también los nombres a pesar de mantener la ambientación sienesa, es ante todo una historia, a despecho del final feliz, patética y dolorosa, fundada en la narración de hechos lastimosos y desgarradores. La inserción de un sinfín de añadidos y modificaciones dificulta, y hasta imposibilita, la referencialidad con el texto de origen bandelliano, como bien atestiguan por ejemplo la secuencia en la que Angelique se entera de la próxima muerte de su hermano o el amplio paréntesis narrativo en que se plantea el problema del asentimiento de la doncella a la pérdida de su virginidad. «C'estoit grand pitié — escribe Belleforest en la primera circunstancia— de voir la belle Angelique se déchirer la face, et arracher les cheueux, voyant qu'il estoit impossible d'oster ceste cruelle délibération de la teste de son frère» (Belleforest, Histoire $X X I$, p. 96b). Y más adelante añade: «Angelique accompagnée de ses parents [...] remplissoit l'air de gemissemens, et crioit comme une forcenée, laquelle estoit suyuie et accompagnée des pleurs et complaintes des autres, qui plaignans la fortune de l'adolescent» (p. 97a). Análogamente el escabroso tema de la cesión de la hermana por parte de Charles se convierte en «un contr'eschange de courtoisie» (p. 108a), respetuoso del principio del libre consentimiento de la joven y a tono con la preanunciada victoria de Anseaume Salimbene sobre sus pasiones concupiscibles.

La profunda conmutación semántica efectuada por Belleforest, la operación de transculturación por él puesta en marcha, crea una especie de unicum, totalmente desaprovechado por Lope. Y con esta afirmación entramos de pleno en el ámbito del proceso genético de la pieza del Fénix, o por decirlo de otro modo, en el problema de qué libro tenía en su "mesilla de noche" el dramaturgo al componer

7 Arnould [2018:19] da noticia de una precedente edición de 1565 (Vincent Norment et Jeanne Bruneau, París), que no he conseguido localizar. 
Los bandos de Sena. Si intrascendente resulta la influencia de la adaptación ejemplarizante ultrapirenaica, tampoco podemos contar en esta ocasión con la intermediación española, puesto que el cuento bandelliano objeto de nuestro interés no forma parte de la lista de catorce novelas vertidas al castellano por Vicente de Millis Godínez y publicadas en 1589 (cfr. Muñoz Sánchez 2013:122-123). Lope, pues, debió de seguir directamente el texto italiano (cfr. González Cañal 2006:407), lo cual, como nos recuerda Guillermo Carrascón, ${ }^{8}$ no debía de ser nada raro, puesto que en un célebre fragmento de una carta escrita al duque de Sessa a mediados de 1613, él mismo se pavoneaba de ser «buen lector de latín, italiano y francés» (Lope de Vega, Cartas, p. 231).

Pero el quid de la cuestión es aquí distinto: en su recomposición de la novella 49 el comediógrafo apuesta por una solución innovadora, basada en un original ensamblaje de los materiales preexistentes y en un ensanchamiento narrativo desvinculado de la tradición. Para poder apreciar el nuevo colorido de su entramado fictivo es suficiente examinar el elenco de las dramatis personae. Lo que salta a la vista no es solo el alto número de personajes, sino también la reduplicación de las parejas. En efecto, el trazado de las figuras no se compone únicamente del dúo Angélica y Pompeyo (el Carlo de las versiones italianas) Montanos, sino que se ve enriquecido por la presencia de Teodora, hermana de Leonardo Salimbene (el Anselmo de los novellieri), y por Lisandro, hijo de Faustino, el senador viejo, sustitutivo del «maligno cittadino» ideado por Bandello. Completa el conjunto una variopinta clase de criados, entre los que destacan Celia, la sirvienta de la casa de los Montanos; Donato, el servidor de los Salimbenes; y Fabio, el leal asistente de Teodora. Aparece, pues, evidente que Lope no se conforma con los tres héroes sin mancha, exempla inigualables de liberalidad y desprendimiento, alrededor de los cuales giraba la parca propuesta narrativa de la novelletta, del mismo modo que no parece interesado en sondear las exquisiteces propias de la quaestio o en escarbar las tortuosas pedreras de la virtud. Su focus de interés es otro, como bien se desprende de los múltiples añadidos y de su incidencia en la construcción de la comedia.

8 «Lope conoció y leyó a los novellieri directamente en sus originales italianos. Esto está claro por lo que se refiere a Bandello aunque no fuera más que porque solo cuatro de las diecisiete novelas del italiano que llevó Lope al teatro habían sido traducidas al español, y aun esas cuatro adaptaciones, si bien siguen en parte la traducción española [...] presentan indicios de que Lope conociese y eventualmente manejase la versión original, junto con otras posibles fuentes» (Carrascón 2018:256). 
«Por más difícil que sea medir y comparar algo tan inaprensible [...] como la "cantidad de historia" que Lope saca de una novella y la cantidad de materia diégetica nueva o de proveniencia diversa [...]»: con estas palabras Carrascón [2017:442] da en el blanco del problema. Si tuviéramos que hacer un balance cuantitativo de lo que el dramaturgo retoma del hipotexto novelístico nos quedaríamos con muy poca cosa. En esta comedia urbana de enredo, la localización — la ciudad de Siena- es solo un elemento insustancial, una cornice para el engaste de su propia trama. El término "bandos" del título alude a la prehistoria del argumento, a la secuela de enfrentamientos y matanzas ocasionadas por el incidente cinegético (Lope de Vega, Los bandos de Sena, vv. 68-82) —este sí recogido de la antigua leyenda-, causa originaria de las rivalidades entre los dos linajes. Siempre al núcleo primigenio de la novelita pertenece el tema de la casa campestre, suscitadora de los desenfrenados anhelos de posesión por parte del ávido ciudadano (Faustino), así como la decisión del joven (Pompeyo) de preferir su propia muerte a la entrega de la finca por «precio vil» (v. 2671). De Bandello parece proceder también el ardid que le permite al codicioso senador, de la facción de los populares, hacerse con la propiedad del desafortunado mancebo, es decir la supuesta infracción del bando en contra de los forajidos (cfr. vv. 797-800; 2179-2187; 2195-2204; 2569-2570), según el cual «qualunque persona tenesse pratica con i confinati per procurar loro il ritorno a la patria pagasse mille fiorini, e non avendo da pagare gli fosse mozza la testa» (Bandello, Novella XLIX, p. 201). Todo lo demás, a partir de cómo se produce el acto de liberalidad por parte de Leonardo - el pago de 2000 ducados de fianza por la excarcelación de Pompeyo-, viene armado por Lope de manera muy distinta.

Sin lugar a dudas, las mayores transformaciones que experimenta la novela en su tránsito a las tablas tienen como pivote la figura de Teodora. Este personaje, enteramente de cuño lopiano, es móvil de la intriga y directora del juego. Mujer lista e ingeniosa, protagoniza la acción a partir de su primera salida a escena, en hábito de hombre, nada más empezar la obra. A ella le debemos toda la información relativa a los antecedentes de la historia (vv. 36-161): en cuanto perteneciente a la casa de los Salimbene, le había caído en suerte acompañar, veinte años atrás, a su hermano Constancio, artífice de las crueles venganzas en contra de los Montanos, durante su exilio por Flandes, Alemania, Italia, hasta dar con sus huesos en Malta, donde estuvo viviendo algún tiempo bajo fingido nombre (Fabricio) y en traje varonil. Allí estuvo hasta cuando, muerto su hermano, decidió asumir su identidad, ha- 
ciéndose llamar Lelio y vistiendo la cruz blanca de los Caballeros hospitalarios de San Juan, para volver por fin, en paños de varón y clandestinamente, a Siena, su patria, donde tendría pensado asentarse, siempre que «la enemistad de estas casas» (v. 153) se lo permita. Es evidente que la dama disfrazada no se corresponde a ninguno de los tipos más representativos señalados en su día por Bravo-Villasante [1988 $: 15]$, es decir la mujer enamorada o la intrépida amazona, en cuanto Teodora no abomina de su sexo, ni puede asociarse al retrato de la doncella andante en busca de su traicionero amante. El «hábito de caballero, con una cruz de San Juan» (Acot.v. 1), prenda que para mayor dificultad «la hace incapaz para el matrimonio» (Cotarelo y Mori 1917:xxiv), es congenial a la necesidad de mantener el anonimato y de retomar paulatinamente las riendas de su propia vida. Huelga decir que el recurso del disfraz complica abundantemente la acción, propiciando las peripecias. En su papel de hombre improvisado, Teodora enamora a Angélica, deja prendado a su hermano Pompeyo, en cuya casa ha sido acogida nada más volver a Siena, y flirtea con Celia, la criada de los Montanos.

Antes de meternos en los vericuetos de la sexualidad transgresiva tan transitados por este personaje, cabe subrayar cómo Lope consigue redirigir, a través de esta figura, el enfoque general de la pieza, alejándola de cualquier empaque moralizador. Teodora, en efecto, no solo le brinda la oportunidad de reduplicar la presencia de lo femenino, sino también de dar vida a una personalidad mucho más arrojada y con una función de claro contrapunto con respecto a Angélica. Al Fénix no debió de hacerle ninguna gracia el papel asignado por la tradición cuentística a la joven Montanini, sujeto sacrificial, aniquilada por las imposiciones del parentesco e inmolada en el altar de un vetusto concepto de honorabilidad, de ahí la necesidad de crear un contramodelo, una mujer tracista, resoluta y que brilla por «agudeza en acción». 9

El primer atractivo de esta «damisela en varón», parafraseando a Tirso (Don Gil de las calzas verdes, v. 24), es el aspecto físico; su rostro barbilampiño, a la par que su pierna airosa, abren brecha en los corazones femeniles, sacándole ventaja a cualquier hombracho corpulento:

9 Afirmaba Gracián (Discurso XLV «De la agudeza por desempeño en el hecho», en Agudeza y arte de ingenio, p. 480): «Consiste el sutilísimo artificio de esta especie de agudeza en hallar el único medio con que salir de la dificultad, en descubrir el raro modo con que desempeñarse». 
CELIA ¡Ay, que tiene un rostro bello, que apenas el primer vello cubre el labio!

Donato ¿De qué modo?

CELIA ¿Nunca has visto una camuesa?

Donato De tu mal gusto me pesa, y de que no te alborote más un gallardo bigote que todo el rostro atraviesa. (vv. 615-622)

La adopción de la identidad varonil raya a menudo en lo inmoral, puesto que en cuanto falso muchacho Teodora / Lelio provoca el enamoramiento tanto de la criada como de su ama, dando vida a escenas de alto contenido erótico, repletas de requiebros y ofrecimientos. En ambas ocasiones el personaje consigue salir de apuros gracias al manto protector de la noche, que le permite introducir en el último momento a un sustituto, capaz de suplantarle en el difícil cometido: «No me lo has de agradecer» — afirma Teodora dirigiéndose a Fabio, su acompañante en el viaje de vuelta a Siena, y cortejador de Celia- «pues que mujer soy, / porque en efeto te doy / lo que no puedo comer» (vv. 1014-1017). Más escabrosas aún son las insinuaciones pronunciadas, siempre al abrigo de la «noche alcahueta» (v. 3135), en la secuencia en que la dama, enfundada en el traje varonil, sirve de tercera a su hermano Leonardo en la cita amorosa con Angélica. «Para que venga a ser tuya / has de fingir que soy yo» (vv. 1202-1203): es así que la "fanciulla en travesti" se esmera en un diálogo apasionado, no exento de toques audaces — los suasorios requiebros a la mano (vv. 1273-1309)—, traspasando empero a su hermano el encargo de besar con ardor a Angélica y de dejarle en prendas su anillo para que pueda reconocerle en el futuro (vv. 1318-1323).

La urgencia pasional, el hechizo nocturno que desata inhibiciones, el travestismo son todos ingredientes definitorios de esta pieza lopiana, desprovistos sin embargo de cualquier anclaje en la tradición de la novella de Angelica Montanini. Desde esta perspectiva no sería ocioso preguntarse sobre la posible interferencia de otra fuente vivificadora de la arquitectura del enredo. La ambigüedad identitaria, la imposibilidad de distingo entre figura femenina andrógina y mozuelo efébico son unos elementa narrationis que entroncan con la práctica teatral de los Intronati de 
Siena. El enlace más vistoso es quizá con la comedia Gl'ingannati, fruto de la colaboración entre varios académicos, representada por primera vez en 1532, e impresa cinco años más tarde en Siena y en Venecia (Curzio Navo, 1537). ${ }^{10}$ La pieza, «modello fondante decisivo per la nascita della commedia moderna in Francia, in Spagna e in Inghilterra» (Pieri 2009:16), gira alrededor de Lelia, la protagonista, dispuesta por amor a asumir una identidad opuesta a su propia naturaleza, bajo el nombre de Fabio. La obra cuenta con un rápido traslado en el área ibérica — Los engañadosgracias a la pluma de Lope de Rueda; el batidor sevillano, además, mantuvo también el nombre de Lelia para la principal figura femenina. Habría que preguntarse si dicha elección repercute — ¿espía onomástica?_ en la decisión del Fénix de que Teodora se haga llamar Lelio, aunque el aspecto más intrigante que escudriñar sea la posible dependencia de Los bandos de la casi inmediata transcripción novelística de Gl'ingannati por parte de Bandello. La comedia lopiana comparte en efecto el mismo espíritu burlón e irreverente que caracterizaba la novella 36 de la Parte II de la colección del dominico - Nicuola, innamorata di Lattanzio,va a servirlo vestita da paggio e dopo molti casi seco si marita, e ciò che ad un suo fratello avvenne-, haciendo propias incluso unas cuantas alusiones —ni siquiera demasiado veladasal amor impossibilis. Significativa al respecto es la sabrosa escena en que Pompeyo supone ser cortejado por el amante travesti, empezando a dudar de sus mismas inclinaciones sexuales (POMPEYo «Lelio, no pensé en mi vida / escuchar amores de hombre», vv. 2007-2008); la secuencia guarda un curioso parentesco con el fallido intento del anciano Gerardo de besar a Paolo, confundido con su hermana cuasi gemela, Nicuola, pese a que el joven acababa de ser por él sorprendido en el acto de galantear a su propia hija. ${ }^{11} \mathrm{Ni}$ duda cabe, pues, de que el tratamiento moralizador de la pasión amorosa no tiene acogida en Lope, por lo menos en Los bandos, pieza lúdica, placentera, en la que el dramaturgo no pone coto a la transgresión, jugando constantemente «en la frontera que separa lo prohibido de lo admitido socialmente»

10 Cfr. Pieri [2009:31-32].

11 «Io t'assicuro che meco averai buon tempo e a te lascerò il governo de la casa. - E dicendo che di lui non poteva aver se non buon trattamento, Paolo diceva tra sé: - Io son pur oggi stato preso due volte in fallo. La figliuola di costui si crede che io sia un suo Romolo e questi pensa che io sia mia sorella; ma la figliuola non si sarà già del tutto ingannata. - Gerardo teneva pur detto: - Nicuola, tu non mi dici nulla? Dimmi l'animo tuo, che io adatterò il tutto. — E volendo basciarlo, Paolo lo rispinse indietro e gli disse: - Se voi volete nulla, parlate con mio padre, e lasciatemi andare, ch'io era venuta qui, non so come. - Il vecchio, che credeva lui essere la Nicuola, disse: - Orsù va, ch'io parlerò a tuo padre, ed ultimerò la pratica» (Matteo Bandello, Novella XXXVI, p. 278). 
(Ferrer Valls 2003:21) e intercalando elementos narrativos de su propia cosecha que modifican y alteran la arquitectura del cuento italiano.

Otra prueba de cómo la situación de ficción imaginada por Bandello le sirve a Lope solo de falsilla para su propia línea diegética puede hallarse en el distinto proceder de Leonardo. Nada se dice en el texto fuente de la doble venganza del joven Salimbene, que no solo castiga con mil azotes a los «dos falsos testigos», responsables del encarcelamiento de Pompeyo (v. 2763), sino que también golpea al senador Faustino donde más le duele, es decir dando fuego a su casa en el campo, el bien más precioso por él poseído y que tanto papel jugó en la fortuna de la antigua novella. Broche de oro de esta comedia, socarronamente ejemplar, es su clausura sellada por las bodas múltiples, en señal de la plena restauración de la paz entre las familias.

Concluyendo, el proceso de apropiación, a través del cual Lope recupera y traslada a medidas dramáticas la materia diegética vehiculada por la novella bandelliana y por sus numerosos antecedentes, tiene su eje vertebrador en la libertad adaptativa y en la creación ex novo de personajes y episodios. Nada, por consiguiente, de reverencial fidelidad al original: la «usual fidelity to his source» ${ }^{12}$ es aquí suplantada por una revisitación libre de ataduras, por un desenvuelto abordaje al núcleo narrativo que dificulta la misma posibilidad de comparativas intertextuales. Pero cuidado, una "comedia no hace ciento", por así decirlo. Lo razonable es recordar que con Lope los límites se hacen fluidos, puesto que lo propio del Fénix fue la independencia de criterio con respecto a sus intereses creadores. En su producción, pues, la abundancia va siempre de la mano de la variedad: «porque comedias en mí es como paños en Segovia, color en Granada, guademeciés en Córdoba y vocablos nuevos en don Lorenzo [Ramírez de Prado]» (Lope de Vega, Cartas, p. 145). Constante explorador de vías inéditas, Lope parece regocijarse con desbarajustar todo compartimiento estanco en que nosotros, sus decodificadores de hoy en día, nos empecinamos en colocarlo.

12 «Convencido — según los preceptos del propio Giraldi- de que las novelas y las obras dramáticas tienen las mismas reglas, Lope conserva sustancialmente el desarrollo de la trama de Cinzio [El piadoso veneciano], y traslada a las tablas todos los episodios centrales del cuento. Recuperando el veredicto de Metford acerca de la "usual fidelity" de Lope "to his source" a la hora de readaptar las novelle de Boccaccio, tenemos que considerar esta práctica como una constante del modus operandi del Fénix con respecto al tratamiento escénico del material novelístico» (Resta y González Ramírez 2013:171). 


\section{BIBLIOGRAFÍA}

Anonimo senese, La storia di Angelica Montanini, en Marchi 2017, pp. 181-198.

ARnould, Jean-Claude, «Les premières éditions des Histoires Tragiques de Pierre Boaistuau (1559-1566)», en Les Histoires tragiques du XVI ${ }^{\mathrm{e}}$ siècle. Pierre Boaistuau et ses émules, ed. J.-C. Arnould, Classiques Garnier, París, 2018, pp. 13-23.

ARRónIZ, Othón, La influencia italiana en el nacimiento de la comedia española, Gredos, Madrid, 1969.

BAdioli, Lorella, «Una declamatio de liberalitate: la novella di Angelica Montanini», en Favole Parabole Istorie. Le forme della scrittura novellistica dal Medioevo al Rinascimento. Atti del Convegno di Pisa 26-28 ottobre 1998, eds. G. Albanese, L. Battaglia Ricci y R. Bessi, Salerno Editrice, Roma, 2000, pp. 419-437.

Bandello, Matteo, Novella XLIX, en Le novelle, ed. G. Brognoligo, Laterza, Bari, 1928, vol. II, pp. 197-219.

Bandello, Matteo, Novella XXXVI, en Le novelle, ed. G. Brognoligo, Laterza, Bari, 1931, vol. III, pp. 249-279.

Bargagli, Scipione, La novella di Angelica Montanini, ed. L. Riccò, Salerno Editrice, Roma, 1991.

BARGaGLI, Scipione, I trattenimenti, ed. L. Riccò, Salerno Editrice, Roma, 1989.

BeLleforest, François de, Histoire XXI, en Le second tome des Histoires tragiques, extraites de l'Italien de Bandel, contenant encore dixhuit Histoires traduites et enrichies outre l'invention de l'Autheur, Robert Le Mangnier, París, 1566, pp. 85b-123b.

Bravo-Villasante, Carmen, La mujer vestida de hombre en el teatro español (Siglos XVI-XVII), Mayo de Oro, Madrid, $1988^{3}$.

CARRAScón, Guillermo, «Otra vez sobre Lope y Bandello», en Hispanismos del mundo. Diálogos y debates en (y desde) el Sur, coord. L. Funes, Miño y Dávila Editores, Buenos Aires, 2016, Anexo digital, Sección II, pp. 47-53.

CARRAscón, Guillermo, «Bandello en el taller dramático de Lope», en Serenísima palabra. Actas del X congreso de la AISO, Venecia 14-18 de julio de 2014, coords. A. Bognolo, F. del Barrio de la Rosa, M.V. Ojeda Calvo, D. Pini y A. Zinato, Edizioni Ca' Foscari, Venecia, 2017, pp. 441-452.

CARRAscón, Guillermo, «Lope y Bandello, entre libertad y censura», en Trayectorias literarias hispánicas: redes, irradiaciones y confluencias, eds. M. Rosso, F. Gambin, G. Calabrese y S. Cattaneo, AISPI Edizioni, Roma, 2018, pp. 255-272. 
Cotarelo y Mori, Emilio, «Prólogo», en Obras de Lope de Vega publicadas por la Real Academia Española (Nueva edición), ed. E. Cotarelo y Mori, Tipografía de la "Revista de Archivos", Madrid, 1917, vol III.

Cracolici, Stefano, «L'etopea di Ginevra, o il Somnium di Bernardo Ilicino», en La letteratura a Siena nel Quattrocento, ed. S. Carrai, S. Cracolici y M. Marchi, ETS, Pisa, 2009, pp. 109-135.

FerRer ValLs, Teresa, «Damas enamoran damas, o el galán fingido en la comedia de Lope de Vega», en Amor y erotismo en el teatro de Lope de Vega. Actas de las XXV Jornadas de Teatro Clásico de Almagro, 9,10 y 11 de julio de 2002, coords. F.B. Pedraza Jiménez, E.E. Marcello y R. González Cañal, Universidad de Castilla-La Mancha, Almagro, 2003, pp. 191-212.

Francalanci, Leonardo, «Il commento di Bernardo Ilicino ai Triumphi di Petrarca e la sua diffusione europea: alcune questione di metodo», Studi di Filologia Italiana, LXIV (2006), pp. 143-154.

Francalanci, Leonardo, «La traduzione catalana del commento di Bernardo Ilicino ai Triumphi del Petrarca: alcune novità a proposito del modello italiano», Quaderns d'Italià, XIII (2008), pp. 113-126.

GonZÁlez CAÑAL, Rafael, «Rivalidades familiares en el teatro del Siglo de Oro. "Los amantes de Verona”", en El Siglo de Oro en escena: homenaje a Marc Vitse, coords. O. Gorsse y F. Serralta, Université de Toulouse II-Le Mirail, Presses Universitaires du Mirail, Toulouse, 2006, pp. 405-418.

Gracián, Baltasar, Agudeza y arte de ingenio, eds. C. Peralta, J.M. Ayala y J.M. Andreu, Prensas Universitarias de Zaragoza - Departamento de Educación, Cultura y Deporte del Gobierno de Aragón, Zaragoza, Instituto de Estudios Altoaragoneses, Huesca, 2004, vol. II.

Guazzo, Stefano, La civil conversazione, ed. A. Quondam, Franco Cosimo Panini, Módena, 1993, vol. I.

Hernández Valcárcel, Carmen, (s.a.), «Presencia del cuento italiano en textos españoles», en línea, <http://www.chvalcarcel.es/MASTER/05\%20Italia\%20y\%20 Esp /5.2.htm>. Consulta del 6 de junio de 2018.

LaPini, Bernardo, La Novella di Angelica Montanini, en Marchi 2017, pp. 83-180.

LoI, Nicola Ignazio, «Riscrivere e rileggere Bandello. Il destino del paratesto tra Histoires tragiques (1559) ed edizione milanese (1560)», en I novellieri italiani e la loro presenza nella cultura europea: rizomi e palinsesti rinascimentali, 
eds. G. Carrascón y C. Simbolotti, Accademia University Press, Turín, 2015, pp. 350-363.

MARChI, Monica, «Un paneretto d'insalatella in rime e in prose: il novelliere senese attribuito a Gentile Sermini», Per leggere, XXI (2011), pp. 57-116.

Marchi, Monica, La storia di Angelica Montanini. Un "topos" della novellistica nel Rinascimento senese, Pacini Editore, Ospedaletto (Pisa), 2017.

Marenduzzo, Antonio, «Notizie intorno a Scipione Bargagli con appendice bibliografica», Bullettino Senese di Storia Patria, VII (1900), pp. 325-347.

Menéndez y Pelayo, Marcelino, Orígenes de la novela. Tomo II, Bailly-Baillière e Hijos, Madrid, 1907.

Menetti, Elisabetta, Enormi e disoneste: le novelle di Matteo Bandello, Carocci, Roma, 2005.

MuÑoz SÁnchez, Juan Ramón, «"Escribía / después de haber los libros consultado”: a propósito de Lope y los novellieri, un estado de la cuestión (con especial atención a la relación con Giovanni Boccaccio), parte II», Anuario Lope de Vega. Texto, literatura, cultura, XIX (2013), pp. 116-149.

Pertici, Petra, «Pseudo Gentile Sermini, Novelle. Edizione critica con commento a cura di M. Marchi, Pisa, ETS, 2012 (2013)», Bullettino Senese di Storia Patria, CXX (2013), «Notiziario bibliografico», pp. 343-349.

PierI, Marzia, «Introduzione», en Accademia degli Intronati, Gl'Ingannati, ed. M. Pieri, Teatrino di Fondi / Titivillus Mostre Editoria, Corazzano (Pisa), 2009, pp. 11-32.

Pseudo Sermini, Gentile, Novella XIV, en Marchi 2017, pp. 71-81.

Resta, Ilaria, y David GonzÁlez Ramírez, «Lope de Vega, reescritor de Giraldi Cinzio: la construcción dramática de una novella de los Hecatommithi», en De este artife. Estudios en honor de Aldo Ruffinatto en el IV centenario de las Novelas ejemplares, eds. G. Carrascón, D. Capra, M.C. Pangallo y I. Scamuzzi, Edizioni dell'Orso, Turín, 2013, pp. 137-148.

RIccò, Laura [1989]: véase Bargagli, Scipione, I trattenimenti.

Riccò, Laura, «La novella e l'assedio di Siena: una questione di famiglia fra teoria, prassi e ricezione», La Rivista, 0 (2013), pp. 85-94.

SANGUineti, Edoardo, «Gli “schemata” del Decameron», en Il chierico organico. Scritture e intellettuali, Feltrinelli, Milán, 2000, pp. 44-57.

Tirso de Molina, pseud. de Gabriel Téllez, Don Gil de las calzas verdes, en Il teatro 
spagnolo dei Secoli d'Oro, vol. I - Lope de Vega Carpio, Tirso de Molina, Miguel de Cervantes, coord. M.G. Profeti, Bompiani, Milán, 2014.

Ugurgieri Azzolini, Isidoro, Le Pompe sanesi, o'vero Relazione delli huomini e donne illustri di Siena e suo stato. Parte II, Pier'Antonio Fortunati, Pistoia, 1649.

Valero Moreno, Juan Miguel, «Sotto le stelle del Petrarca: vidas cruzadas (un episodio del petrarquismo en España)», Revista de Filología española, LXXXIX 2 (2009), pp. 329-348.

Vega Carpio, Lope de, Los bandos de Sena, Biblioteca Virtual Miguel de Cervantes, Alicante, 2004, ed. digital a partir de Veintiuna parte verdadera de las comedias de Lope de Vega Carpio, Viuda de Alonso Martín, Madrid,1635.

Vega CARPIo, Lope de, Cartas (1604-1633), ed. A. Carreño, Cátedra, Madrid, 2018. 